\title{
Examining food insecurity and areas with unmet food needs during COVID-19: A geospatial, community-specific approach
}

\author{
Kathryn M. Janda ${ }^{\text {a }}$ and Raven Hood ${ }^{\mathrm{b}}$ \\ UTHealth School of Public Health and Michael \\ and Susan Dell Center for Healthy Living
}

Amy Price ${ }^{\mathrm{c}}$

United Way for Greater Austin

Samantha Night ${ }^{d}$

Central Texas Food Bank

\author{
William Edwin Marty ${ }^{e}$ and Amanda Rohlich ${ }^{f}$ \\ City of Austin Office of Sustainability
}

Kacey Hanson $g$ and Marianna Espinoza $h$

University of Texas at Austin Dell Medical

School Population Health Department

Alexandra E. van den Berg ${ }^{\mathrm{i}}$

UTHealth School of Public Health and Michael and Susan Dell Center for Healthy Living

Submitted October 1, 2020 / Revised February 9 and April 5, 2021 / Accepted April 5, 2021 /

Published online June 24, 2021

Citation: Janda, K. M., Hood, R., Price, A., Night, S., Marty, W. E., Rohlich, A., Hanson, K., Espinoza, M., \& van den Berg, A. E. (2021). Examining food insecurity and areas with unmet food needs during COVID-19: A geospatial, community-specific approach. Journal of Agriculture, Food Systems, and Community Development, 10(3), 55-67. https://doi.org/10.5304/jafscd.2021.103.017

Copyright (C) 2021 by the Authors. Published by the Lyson Center for Civic Agriculture and Food Systems. Open access under CC-BY license.

a * Corresponding author: Kathryn M. Janda, PhD, MPH

Postdoctoral Fellow, UTHealth School of Public Health, Michael and Susan Dell Center for Healthy Living; University of Texas Administration Building (UTA); 1616

Guadalupe, Suite 6.300; Austin, TX 78701 USA; +1-734-5606829; Kathryn.M.Janda@uth.tmc.edu

b Raven Hood, MPH, Graduate Research Assistant. UTHealth School of Public Health; and MPH Postdoctoral Fellow, UTHealth School of Public Health, Michael and Susan Dell Center for Healthy Living; ravhood@gmail.com

c Amy Price, Navigation Center Vice President. United Way for Greater Austin; Amy.Price@uwatx.org

d Samantha Night, MPAff, Project Manager, Central Texas Food Bank; snight@,centraltexasfoodbank.org

e William Edwin Marty. Food Policy Manager, City of Austin Office of Sustainability; Edwin.Marty@austintexas.gov

${ }^{\mathrm{f}}$ Amanda Rohlich, MPA, Food Policy Advisor, City of Austin Office of Sustainability; Amanda.Rohlich@austintexas.gov

g Kacey Hanson, MPH, Program Manager, University of Texas at Austin Dell Medical School Population Health Department; Kacey.Hanson@austin.utexas.edu h Marianna Espinoza, MPH, Learning and Evaluation Manager of Community-Driven Initiatives, University of Texas at Austin Dell Medical School Population Health Department; Marianna.Espinoza@austin.utexas.edu

i Alexandra E. van den Berg, PhD, MPH, Professor of Health Promotion and Behavioral Sciences, UTHealth School of Public Health; and Associate Director, Michael and Susan Dell Center for Healthy Living;

Alexandra.E.VanDenBerg@uth.tmc.edu

\section{Disclosures and Disclaimers}

The authors have no potential conflicts of interest to disclose. This work was funded by the City of Austin. The content is solely the responsibility of the authors and does not necessarily represent the official views of the National Cancer Institute or the National Institutes of Health.

\section{Funding Disclosure}

The authors would like to acknowledge the City of Austin Office of Sustainability for their funding of this research. This work was completed while Dr. Janda was a postdoctoral fellow with the University of Texas Health Science Center at Houston School of Public Health Cancer Education and Career Development Program, funded by National Cancer Institute/National Institute of Health grant T32/CA057712. 


\begin{abstract}
Food insecurity is a public health issue that has increased in the U.S. since the 2020 COVID-19 pandemic. Understanding how this increase occurs locally is crucial in informing appropriate food insecurity-related responses. Analyzing 2-1-1 call data is one way to examine food insecurity-related needs at a zip code level. The purpose of this work was to: (1) examine overall call trend data to 2-1-1 from March through July 2019 and March through July 2020, (2) examine changes in food need call volume to 2-1-1 during COVID-19 by zip code, and (3) identify areas with unmet food needs during COVID-19 in central Texas. Data for 2-1-1 calls from Travis County zip codes for March through July 2020 were compared to calls for March through July 2019 and categorized by reason for calling. Descriptive statistics and paired ttests were used to analyze food need calls by zip code and mapped using ArcGIS. Communities with high food call volume and no emergency food assets located within the zip code were categorized as areas with unmet food needs. Results indicated there were more overall calls to 2-1-1 in 2020 $(N=37,572)$ than in $2019(N=28,623)$, and significantly more food need calls in 2020 than in 2019 $(p<0.01)$. Eastern Travis County, a racially and ethnically diverse and lower-income area, had the largest increase in food need calls. Two zip codes were identified as having unmet food needs, which informed the strategic placement of emergency food assets. This study illustrates how 2-1-1 data can result in rapid translation of research to policy and program implementation.
\end{abstract}

\section{Keywords}

2-1-1 Calls, Community Health, COVID-19, Pandemic, Food Insecurity, Health Disparities

\section{Introduction and Literature Review}

Food insecurity is defined as the inconsistent access to a sufficient amount of food to live an active and healthy life (Pinstrup-Andersen, 2009). While considered a wealthy nation, the United States had high rates of household food insecurity prior to the outbreak of the novel coronavirus (COVID-19), with $11.1 \%$ of households identifying as food insecure in 2018 (United States
Department of Agriculture Economic Research Service [USDA ERS], 2019). Since the start of the COVID-19 pandemic, the prevalence of food insecurity has increased dramatically in the U.S. (Niles et al., 2020; Schanzenbach \& Pitts, 2020; Wolfson $\&$ Leung, 2020). Research conducted by Northwestern University found that domestic food insecurity has more than doubled to $25.5 \%$ during the COVID-19 pandemic (Schanzenbach \& Tomeh, 2020). Similar to national statistics, food insecurity prevalence in Texas has doubled, with over $28 \%$ of Texans identifying as food insecure in April through June 2020 (Schanzenbach \& Tomeh, 2020). To address the rising rates of food insecurity, local officials need rapid and local data to inform local policies and strategic implementation of food insecurity mitigation programs. The purpose of this paper is to describe how a novel data collection method can be used to rapidly identify areas experiencing unmet food needs and inform programming and policies during the pandemic.

\section{Food Insecurity and Disparities Prior to and During COVID-19}

Food insecurity is often the byproduct of poverty or economic disadvantage and does not occur in isolation (Bhattacharya et al., 2004; Finney Rutten et al., 2010; Gundersen et al., 2011). Additionally, food insecurity prevalence has historically increased during high unemployment and/or economic recession (Andrews \& Nord, 2009; Loopstra et al., 2016). Some scholars identified that the combination of high unemployment rates, economic downturn, stay-at-home orders, school closures (and consequently the reduced offering of school nutrition programs), closure and/or limited hours of food retail, and social distancing policies during COVID-19 have had a particularly dramatic impact on food insecurity (Choudhury et al., 2020; Dunn et al., 2020; Laborde et al., 2020; Pérez-Escamilla et al., 2020; Shanks et al., 2020; Wolfson \& Leung, 2020).

Before the pandemic, people of color and lowincome households were more likely to be food insecure than people who lived in white and/or more wealthy communities (Hernandez et al., 2017; Odoms-Young \& Marino, 2018; Seligman \& Schillinger, 2010). Additionally, communities of 
color and low-income areas are more likely to have limited geographic food access, meaning that they typically do not have healthy food retail options in their neighborhoods and have to travel farther to access food (Alkon \& Agyeman, 2011; Larson et al., 2009; Morales, 2011; Walker et al., 2010). These disparities are evident in central Texas, where eastern Travis County, largely due to historic redlining practices, has generally had a larger population of Black and Hispanic communities, lower median household income, fewer healthy food retail opportunities, and a higher prevalence of food insecurity than western Travis County (City of Austin Office of Sustainability, 2019; City of Austin Travis County Health and Human Services Department, 2015; Huggins, 2017; United Way of Central Texas, 2019; U.S. Census Bureau, 2018).

Since the start of the COVID-19 pandemic, national and state-level food insecurity data suggest that disparities between racial and ethnic groups are increasing (Morales et al., 2020). Individuals who identify as Black $(34.9 \%)$ and Hispanic American $(34.0 \%)$ have been found to have a much higher prevalence of food insecurity during COVID-19 than white Americans (25.5\%) at the national level (Schanzenbach \& Tomeh, 2020). Furthermore, state-level analyses using Census Pulse Survey data found that Black (35.2\%) and Hispanic (33.2\%) Texans have a higher prevalence of food insecurity than White Texans $(21.6 \%$ ) (Schanzenbach \& Tomeh, 2020). These findings demonstrate that pre-existing food insecurity disparities could be widening during the pandemic; however, there is limited data about food insecurity rates at a local or zip code level. The smallest geographic unit of analysis for food insecurity data during the pandemic has been at the county-level, and it is projected that food insecurity in Travis County has risen significantly during the COVID-19 pandemic (Gundersen et al., 2020). However, determining food insecurity prevalence at a more local level, such as by zip code or census tract, is often only available in national data sets and takes years to become available (Coleman-Jensen et al., 2018). Thus, community-specific food insecurity data is necessary to ensure that all high need areas have additional food assets available during the pandemic and that pre-existing disparities do not widen.
One solution for decreasing food insecurity is to connect individuals who have emergency and chronic food needs to resources that address food insecurity, such as food banks, food pantries, soup kitchens, the Supplemental Nutrition Assistance Program (SNAP, formerly known as food stamps), and hotlines or call lines that can connect individuals to needed resources (Bacon \& Baker, 2017; Boyum et al., 2016; Linnan, 2012; O'Connell et al., 2008; Robaina \& Martin, 2013).

\section{Food Insecurity Resources and the United Way 2-1-1 Call Line}

One resource that has successfully facilitated network building and resource referrals for individuals in need for the last two decades has been the United Way's 2-1-1 call line program (Daily, 2012). Established in 2000 by the Federal Communications Commission (FCC), the network of 2-1-1 call line programs became operational in all 50 states and Puerto Rico during the next decade (Daily, 2012; Linnan, 2012). By 2018, 2-1-1 call lines were considered a well-established resource for the community throughout the country. For example, in 2018, the United Way for Greater Austin received over 50,000 2-1-1 calls, of which approximately $11 \%$ regarded food insecurity-related issues (Janda et al., 2020). United Way considers all callers to 21-1 to be clients of United Way.

The United Way for Greater Austin operates the 2-1-1 call line in Travis County. Since the start of the pandemic, United Way has helped disseminate information pertaining to COVID-19 through the central Texas region (United Way for Greater Austin, 2020a, 2020b). In Texas, 2-1-1 is considered a key COVID-19 information resource publicized by billboards, radio, and many government officials' public addresses, including Governor Abbott and City of Austin officials (Weber, 2020). Additionally, United Way for Greater Austin kept consistently updated records on the location and availability of emergency food assets and open resources during the COVID-19 pandemic (United Way for Greater Austin, 2020b).

United Way for Greater Austin/2-1-1 also collaborated with Austin Public Health and the City of Austin Office of Sustainability's Food Policy Team (which existed prior to COVID-19) to help coordi- 
nate responses to local food systems issues. The Food Access Coordination Taskforce, led by the City of Austin Office of Sustainability, became crucial in this coordination and consists of approximately two hundred individual contacts representing city and county departments, school districts, nonprofits, and community-based organizations. The taskforce met weekly to share updates on organizational operations, identify areas of need (including opportunities for collaboration and directing resources), and develop a longer-term strategy to address the anticipated increase in food access needs throughout the community after the pandemic. However, the taskforce realized that it needed more data to understand how food insecurity was changing at a community level throughout the county and to inform policy and program implementation.

\section{Gaps in the Literature and Community Needs} At the start of the pandemic, there were no datasets or reports available that included data regarding what areas of Travis County were experiencing especially high food insecurity rates. 2-1-1 call data were identified by the City of Austin and other collaborators as a potentially valuable source for information regarding food needs that could provide zip-code level data and could be paired with geographic food asset location data. Additionally, these data could fill a notable gap to better inform policies and programs to strategically place assets in areas with high food insecurity needs. Thus, in early April 2020, the City of Austin Office of Sustainability contacted UTHealth School of Public Health in Austin and Dell Medical School to utilize 2-1-1 call data to examine changes in food needs in Travis County and identify areas with unmet food needs in Austin during COVID-19.

\section{Research Objective}

The objective of this work was to build a transdisciplinary collaboration that could: (1) examine overall call trend data to 2-1-1 in March-July 2019 and March-July 2020, (2) examine changes in food need call volume to 2-1-1 during COVID-19 by zip code, and (3) identify areas with unmet food needs during COVID-19 in Travis County, Texas.

\section{Applied Research Methods}

\section{Study Design and Study Area}

The study design was a natural experiment and utilized 2-1-1 call data from Travis County, Texas, during March-July 2019 and March-July 2020, with 2019 dates considered a pre-COVID-19 comparison. Participants were callers to the 2-1-1 call line from March 1 through July 31, 2019, and March 1 through July 31, 2020. The 2020 time frame was selected because awareness of COVID19 gained traction in early March 2020; federal, state, county, and city COVID-19 policies were announced, and the closure of universities, schools, and large events all started occurring in Travis County (Weber, 2020).

The sample was restricted to those who made calls to the United Way for Greater Austin in the aforementioned time frame from Travis County, Texas. Callers who did not specify their county of residence, who did not specify their zip code of residence, or who reported a post office box-only zip code as an address were dropped from the analysis. Data about emergency food assets were obtained from collaborators at the United Way for Greater Austin and the City of Austin Office of Sustainability. This study was approved and considered exempt by the Institutional Review Board (IRB) at UTHealth School of Public Health (HSCSPH-20-0518) because the callers were unidentifiable, and there was no way to follow-up with callers. Furthermore, the IRB determined that consent was implied because all callers to the 2-1-1 call line are informed that information regarding the nature of their call will be included in 2-1-1's call log and records.

\section{Examination of Overall and Food Need 2-1-1 Call Data Methodology}

\section{Call data categorizations}

All 2-1-1 calls used in this analysis were categorized into thematic groups based upon the resources requested by the caller. The thematic categories were finance and unemployment, food needs, health and mental health, housing, transportation, utilities, and other related calls. For this analysis, food need calls to the 2-1-1 call line served as a 
proxy for food. Examples of food need calls included callers looking for food pantries, soup kitchens, food banks, food assistance (such as the Supplemental Food Nutrition Assistance Program and Pandemic-EBT), and other food-specific resources. Demographic data, including the caller's zip code, sex, and language spoken during the call, were noted in the call $\log$ and were self-reported by the caller. No other identifiable data were included in the call log.

\section{Call data analysis}

Descriptive statistics and paired t-tests were utilized for this analysis. Frequencies were calculated for March-July 2019 and March-July 2020 by call categories, demographic information included in the 2-1-1 call log, and zip code. To contextualize call trends longitudinally during the pandemic, overall and food need call volumes were also analyzed by week. Paired t-tests by zip code were calculated to determine if there were statistically significant differences in the mean number of food need calls by zip code in March-July 2019 to March-July 2020. The change in the percent of food need calls by zip code was calculated and then mapped using ArcGIS (ESRI, 2019). All frequencies and t-tests were run utilizing Stata (version 14) (StataCorp, 2015), graphs were made using R ( R Team, 2017), and maps were created with ArcGIS (ESRI, 2019; StataCorp, 2015; R Team, 2017).

\section{Methodology for Identifying Areas with Unmet Food Needs}

Location of emergency food assets was needed to identify areas with unmet food needs. United Way for Greater Austin and the City of Austin Office of Sustainability provided information on the location and addresses of these assets. These locations were consistently updated during MarchJuly 2020 to reflect potential changes in operation. These locations were then geocoded using ArcGIS and included in the analysis for identifying zip codes with

\section{Table 1. Call-Level Descriptive Statistics for March-July 2019} and March-July 2020

\begin{tabular}{|c|c|c|c|c|}
\hline \multirow[b]{2}{*}{ Overall Call Volume } & \multicolumn{2}{|c|}{ March-July 2019} & \multicolumn{2}{|c|}{ March-July 2020} \\
\hline & $N=28,623$ & Percent & $N=37,572$ & Percent \\
\hline \multicolumn{5}{|l|}{ Call Need Categories } \\
\hline Food & 6,667 & $23.29 \%$ & 13,197 & $35.13 \%$ \\
\hline Health/Mental Health & 8,606 & $30.07 \%$ & 10,327 & $27.49 \%$ \\
\hline Housing & 5,086 & $17.77 \%$ & 7,385 & $19.66 \%$ \\
\hline Finance/Unemployment & 2,810 & $9.82 \%$ & 3,942 & $9.02 \%$ \\
\hline Utilities & 2,129 & $7.44 \%$ & 2,409 & $6.41 \%$ \\
\hline Transportation & 1,689 & $5.90 \%$ & 512 & $1.36 \%$ \\
\hline Other & 6,073 & $21.22 \%$ & 6,688 & $17.8 \%$ \\
\hline \multicolumn{5}{|l|}{ Demographics } \\
\hline \multicolumn{5}{|l|}{ Gender } \\
\hline Male & 7,539 & $26.34 \%$ & 10,644 & $28.33 \%$ \\
\hline Female & 20,737 & $72.45 \%$ & 26,353 & $70.14 \%$ \\
\hline Uncertain & 347 & $1.21 \%$ & 575 & $1.53 \%$ \\
\hline \multicolumn{5}{|l|}{ Preferred Language } \\
\hline English & 24,753 & $86.48 \%$ & 31,075 & $82.71 \%$ \\
\hline Spanish & 3,804 & $13.29 \%$ & 6,436 & $17.13 \%$ \\
\hline Other & 66 & $0.23 \%$ & 61 & $0.16 \%$ \\
\hline
\end{tabular}


ing 2-1-1 (35.13\%), followed by health and mental health calls $(27.49 \%)$. During both periods, callers were predominantly female (2019: 72.45\%, 2020: 70.14\%) and spoke English (2019: 86.48\%, 2020: $82.71 \%$ ) or Spanish (2019: 13.29\%, 2020: 17.13\%). The 2-1-1 call line navigators do not ask about the caller's race and/or ethnicity and income level; therefore, that information could not be provided. However, information regarding sociodemographic composition (including race/ethnicity, income level, etc.) by zip code for Travis County is provided by the 2018 American Community Survey and can be found in Figure A in the Appendix.

To better contextualize the call trends longitudinally during the COVID-19 pandemic, overall and food need call data were also analyzed by week (Figure 1). Overall call volume increased sharply during the middle of March, peaked the week of April 12, 2020, and then fluctuated with smaller increases in overall call volume at the end of April and beginning of May, and in early July. Food need call volume also rose sharply in mid-March, peaked the week of May 3, 2020, and consistently declined with small increases in early July. The large increase in food need calls in April and May was mostly due to calls regarding food assistance benefits, such as SNAP.

\section{Changes in Food Calls to 2-1-1 during COVID-19 by Zip Code}

During March-July 2019 and March-July 2020, callers to 2-1-1 resided in 69 zip codes of Travis County. Results from the paired t-tests found that there were statistically significant differences in food need call volume $(\mathrm{t}=-4.93, \mathrm{df}=68, p<0.01)$ and percentage of food need calls $(\mathrm{t}=-5.77, \mathrm{df}=$ 68, $p<0.01$ ) in zip codes from 2019 to 2020 . Thus, there were significantly more food need calls to 2 1-1 across Travis County during the COVID-19 pandemic than there were during the same months in 2019.

The changes in percent of food need calls by zip code were calculated and then mapped (Figure $2)$. Over $78 \%$ of zip codes $(n=54)$ saw an increase in the percentage of food need calls made to 2-1-1 during 2020 compared to 2019. Additionally, over half the zip codes $(n=36)$ saw an increase greater than $10 \%$ in the percentage of food need calls made in the zip code during March-July 2020 compared to March-July 2019, as shown in red and

\section{Figure 1. Overall and Food Call Data by Week, March 1-July 31, 2020}

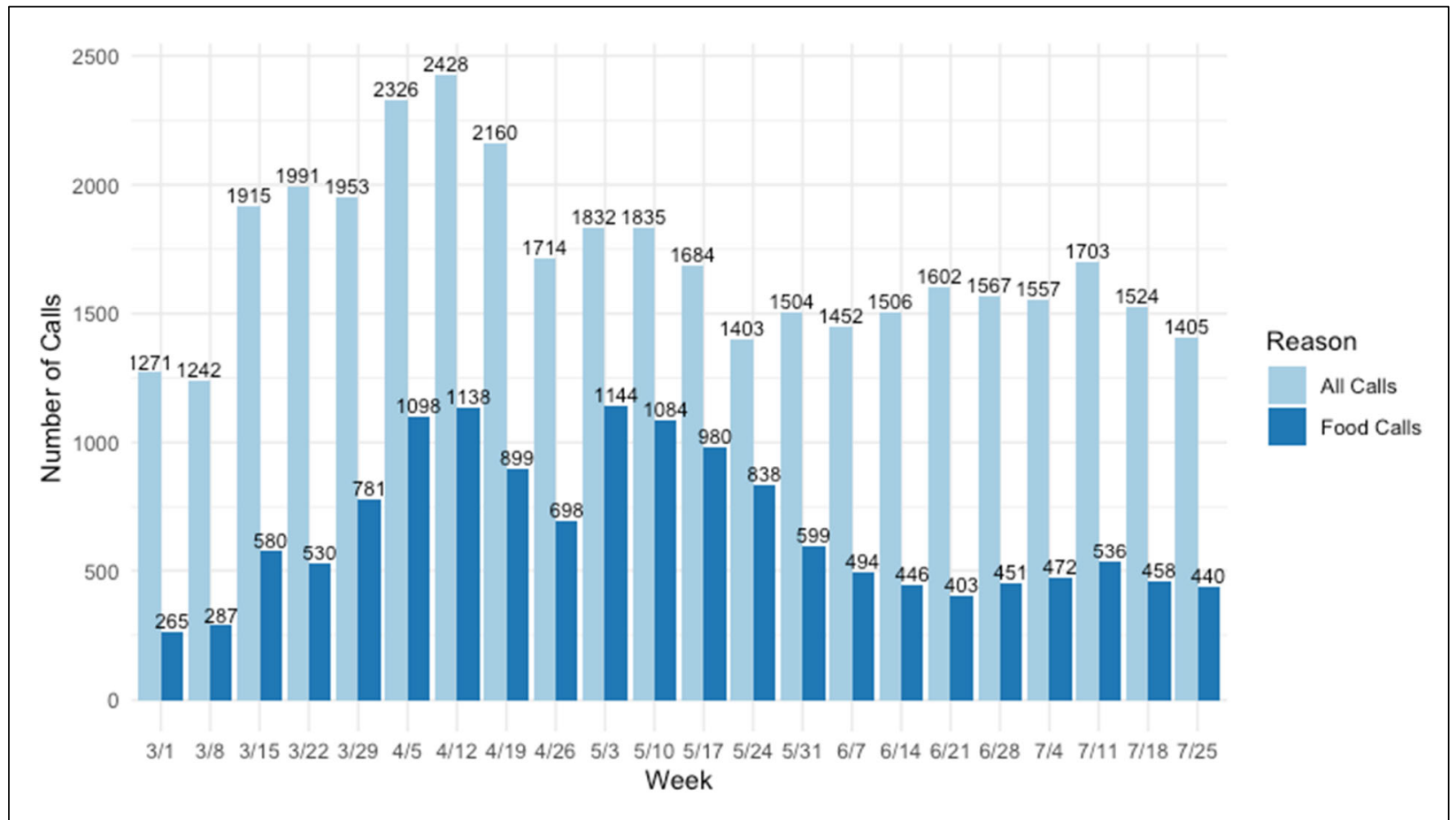


scarlet in Figure 2. Eastern Travis County has more zip codes in dark orange and red than western Travis County.

\section{Identification of Areas with Unmet Food Needs} The final component of this analysis was to identify areas with unmet food needs during the pandemic in Travis County. Geographic analyses of food need calls were compared to locations of open emergency food assets monthly. Zip codes with potential unmet food needs were identified if they had a high overall food need call volume (more than 191 food need calls), a high proportion of food need calls (over 29\% of calls regarded food needs in the zip code), an over 10\% increase in volume and percent of food need calls in MarchJuly 2020 compared to March-July 2019, and lack of an operating emergency food asset located in the zip code from March-July 2020. Two zip codes met the aforementioned criteria. These zip codes were identified by City of Austin officials and other stakeholders as needing a strategically placed food asset during the pandemic.

\section{Discussion}

\section{Summary and Implications of Findings}

\section{2-1-1 overall and food need call level findings and implications}

The purpose of this component of the analysis was to examine overall call trend data to 2-1-1 during March-July 2019 and March-July 2020 and to examine changes in food need call volume to 2-1-1

Figure 2. Changes in Percent of Food Need Call Volume by Zip Code, March-July 2019 to March-July 2020

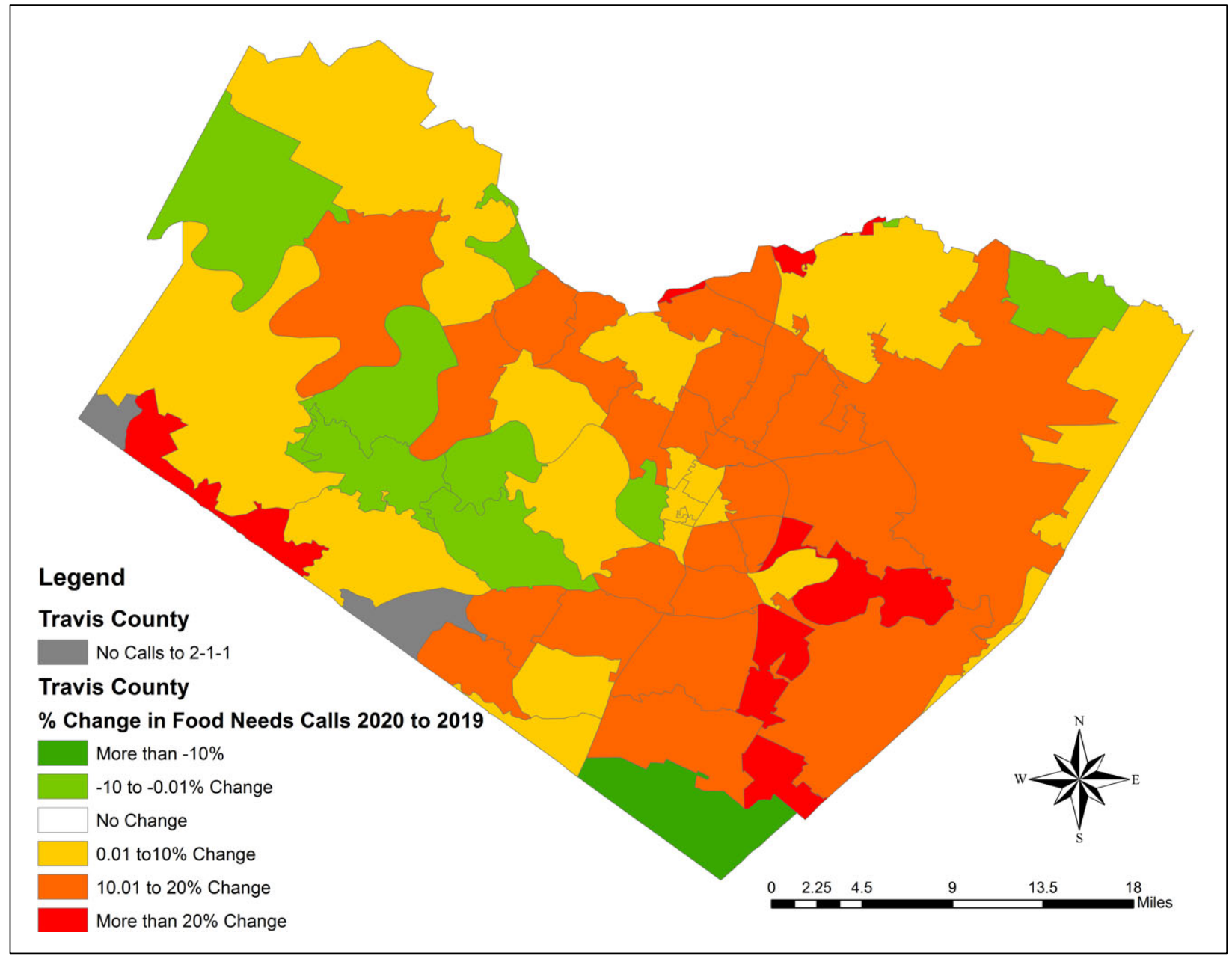


during COVID-19 by zip code. The results showed higher overall call volume and significantly higher food need call volume throughout Travis County during the COVID-19 pandemic. While there was an increase in overall call volume, the category with the greatest percent increase from 2019 to 2020 was food need calls. Additionally, results from the weekly call analysis shed greater insight on public response to key policy announcements and reports about the prevalence of COVID-19 cases and hospitalizations. The first "Stay Home, Stay Safe" order for Austin and Travis County was announced in late March and was extended in midApril. Interestingly, the rise in call volume in June and July matches the reporting of a spike in cases in the Travis County area during that time (City of Austin, 2020; Osborn, 2020; Weber, 2020). Additionally, the peak of food need calls in early May coincides with the first announcement about Pandemic-EBT (Office of the Texas Governor, 2020). Thus, the results demonstrate an increase in calls to 2-1-1 during COVID-19 compared to before the pandemic and that local policy changes and announcements correlate to a rise in 2-1-1 call volume.

While an increase in food need calls using 2-11 data is not a precise or validated measurement of the prevalence of food insecurity, the results demonstrate that food insecurity-related issues and needs are being experienced by a growing number of United Way clients. Additionally, this increase is consistent with the projected increases in food insecurity calculated by Feeding America and the increased prevalence of food insecurity experienced by Americans and Texans found in the Census Pulse Survey analysis (Feeding America, 2020; Schanzenbach \& Tomeh, 2020). This dramatic rise in food insecurity is alarming, given that it has taken 10 years to recover to pre-Great Recession levels (Gundersen et al., 2020).

Results show a greater increase in food need call volume and the change in the proportion of food need calls from 2019 to 2020 in eastern Travis County than in western Travis County. This is an important distinction because eastern Travis County has been identified as a historically underserved and racially and ethnically diverse area with a higher prevalence of food insecurity than western
Travis County (U.S. Census Bureau, 2018). Thus, these findings demonstrate that COVID-19 could be widening the food-insecurity disparities in Travis County and the greater Austin area that existed before the pandemic.

Implications of identification of areas with unmet food needs The third aim of this analysis was to identify areas with unmet food needs during the COVID-19 pandemic in Travis County. This analysis was also able to provide timely and zip-code level recommendations to government officials and nonprofit organizations to implement programs and strategies to potentially ameliorate food insecurity in areas with unmet food needs. The researchers $(\mathrm{KJ}, \mathrm{AB})$ disseminated their findings through monthly reports to the City of Austin (SN, WEM, AR), United Way for Greater Austin (AP), Dell Medical School (KH, $\mathrm{ME})$, the City of Austin Food Access Coordination Taskforce, and other collaborators. They also recommended strategically placing an emergency food asset in the two zip codes with unmet food needs. Due to sharing these results and findings, a local nonprofit organization has strategically placed an emergency food asset in one of the identified areas as of late September 2020, and other county and city officials have utilized these data as rationale for additional funding for existing but overburdened resources. Also, this work has informed where other studies should concentrate sampling for their research (KH, ME). Future research should dive deeper into what factors contribute to these communities' increased proportion of food need calls and how this informs additional policies.

\section{Implications of methodological approach}

This methodology provided a rapid translation of research to policy and program implementation and has implications for food insecurity research. As discussed previously, food-insecurity data often takes years to obtain, analyze, and disseminate, especially at a granular level such as by zip code. This methodology has enabled close to real-time analysis of food needs at a countywide and zipcode level, resulting in the ability to strategically place additional emergency food assets in areas with unmet food needs. This methodology has potential for implementation across the U.S., given 
the nationwide presence of United Way and 2-1-1 call lines to provide local insight into how food insecurity is changing during COVID-19.

\section{Limitations of Study}

There are certain limitations to this study. There are potential threats to the validity of this sample, specifically selection bias and limited generalizability. Since inclusion in this sample required an individual to be aware of and call the 2-1-1 line operated by United Way for Greater Austin, this sample is most likely predominantly low-income, resulting in selection bias. While there were campaigns to promote the utilization of 2-1-1 during this period, it is still unlikely that all Travis County residents experiencing food insecurity were calling 2-1-1 during this time. The sample was predominantly female and English-speaking; therefore, these findings may not be generalizable to all Travis County residents. This was a natural experiment, and so a randomly selected sample was not possible to obtain. While the findings are generalizable to the population of 2-1-1 callers in Travis County, future research could expand on these findings with a more representative sample from the county.

Additionally, food need calls were used as a proxy for food insecurity-related issues, which, while used in previous analyses with 2-1-1 call data, is not a validated food-insecurity measurement (Janda et al., 2020). Adding validated food insecurity items as part of the 2-1-1 call protocol, such as the USDA 18-item measure, or two-item food insecurity screener, would result in a more precise measurement of the prevalence of food insecurity among callers (Gundersen et al., 2017; Jones et al., 2013; Pinstrup-Andersen, 2009). Future work should explore rising trends in food insecurity and widening disparities during COVID-19 with a more representative sample to minimize selection bias and should utilize validated food-insecurity survey instruments to more precisely measure food insecurity.

\section{Conclusions}

Research indicates that food insecurity is increasing during COVID-19 throughout the U.S. Results from this study indicate that these projected increases occur at the local level in central Texas and potentially widen pre-existing disparities during the pandemic. Additionally, this study demonstrates that cross-sector collaboration and utilization of this methodology of analyzing 2-1-1 call data at the zip-code level can result in rapid translation of research into policy. Thus, greater research and transdisciplinary and sector partnership are needed to gain a more nuanced understanding of how food insecurity is increasing at a local level and to subsequently inform effective program and policy implementation.

\section{Acknowledgments}

This work would not have been possible without the support of United Way for Greater Austin and its tireless work with ConnectATX.org and the City of Austin Emergency Food Coordination Committee.

\section{References}

Alkon, A. H., \& Agyeman, J. (2011). Cultivating food justice: Race, class, and sustainability: MIT Press. https://doi.org/10.7551/mitpress/8922.001.0001

Andrews, M. S., \& Nord, M. (2009, December 01). Food insecurity up in recessionary times. Amber Waves. https://www.ers.usda.gov/amber-waves/2009/december/food-insecurity-up-in-recessionary-times/

Bacon, C. M., \& Baker, G. A. (2017). The rise of food banks and the challenge of matching food assistance with potential need: Towards a spatially specific, rapid assessment approach. Agriculture and Human Values, 34(4), 899919. https://doi.org/10.1007/s10460-017-9783-y

Bhattacharya, J., Currie, J., \& Haider, S. (2004). Poverty, food insecurity, and nutritional outcomes in children and adults. Journal of Health Economics, 23(4), 839-862. https://doi.org/10.1016/j.jhealeco.2003.12.008

Boyum, S., Kreuter, M. W., McQueen, A., Thompson, T., \& Greer, R. (2016). Getting help from 2-1-1: A statewide study of referral outcomes. Journal of Social Service Research, 42(3), 402-411. https://doi.org/10.1080/01488376.2015.1109576 
Campbell, C. C. (1991). Food insecurity: A nutritional outcome or a predictor variable? The Journal of Nutrition, 121(3), 408-415. https://doi.org/10.1093/in/121.3.408

Choudhury, P., Koo, W., Li, X., Kishore, N., Balsari, S., \& Khanna, T. (2020). Food security and human mobility during the Covid-19 lockdown (Harvard Business School Technology \& Operations Mgt. Unit Working Paper No. 20113). https://doi.org/10.2139/ssrn.3600376

City of Austin. (2020, March 24). Stay home—work safe (Order No. 20200324-007). The Mayor of the City of Austin. https://www.austintexas.gov/sites/default/files/files/Order\%2020200324007\%20-\%20Stay $\% 20$ Home $\% 20-\% 20$ Work $\% 20$ Safe.pdf.

City of Austin Office of Sustainability. (2019). Food access in Austin. https://www.arcgis.com/apps/Cascade/index.html?appid=ddf4807ce0ad4304a8fef38f769ab14b

City of Austin/Travis County Health and Human Services Department. (2015). 2015 Critical health indicators report. http://www.austintexas.gov/sites/default/files/files/Health/Info to Post/Critical Health Indicators 2015.pdf

Coleman-Jensen, A., Rabbitt, M. P., Gregory, C. A., \& Singh, A. (2018). Household food security in the United States in 2017 (Report No. ERR-256). USDA Economic Research Service. https://www.ers.usda.gov/publications/pub-details/?pubid=90022

Daily, L. S. (2012). Health research and surveillance potential to partner with 2-1-1. American Journal of Preventive Medicine, 43(6), S422-S424. https://doi.org/10.1016/i.amepre.2012.09.021

Dunn, C. G., Kenney, E., Fleischhacker, S. E., \& Bleich, S. N. (2020). Feeding low-income children during the Covid-19 pandemic. New England Journal of Medicine, 382(18), e40. https://doi.org/10.1056/NEJMp2005638

ESRI. (2019). ArcGIS Deskptop: Version 10.7.1 [Computer Software]. Environmental Systems Research Institute, Inc. https://www.esri.com/en-us/home

Feeding America. (2020, September 2020). The impact of coronavirus on food insecurity. https://www.feedingamerica.org/research/coronavirus-hunger-research

Finney Rutten, L. J., Yaroch, A. L., Colón-Ramos, U., Johnson-Askew, W., \& Story, M. (2010). Poverty, food insecurity, and obesity: A conceptual framework for research, practice, and policy. Journal of Hunger \& Environmental Nutrition, 5(4), 403-415. https://doi.org/10.1080/19320248.2010.527275

Franklin, B., Jones, A., Love, D., Puckett, S., Macklin, J., \& White-Means, S. (2012). Exploring mediators of food insecurity and obesity: A review of recent literature. Journal of Community Health, 37(1), 253-264. https://doi.org/10.1007/s10900-011-9420-4

Gundersen, C., Dewey, A., Engelhard, E., Strayer, M., \& Lapinski, L. (2020). Map the meal gap 2020: A report on county and congressional district food insecurity and county food cost in the United States in 2018. Feeding America. https://www.feedingamerica.org/sites/default/files/202006/Map $\% 20$ the $\% 20 \mathrm{Meal} \% 20 \mathrm{Gap} \% 202020 \% 20$ Combined $\% 20$ Modules.pdf

Gundersen, C., Engelhard, E. E., Crumbaugh, A. S., \& Seligman, H. K. (2017). Brief assessment of food insecurity accurately identifies high-risk US adults. Public Health Nutrition, 20(8), 1367-1371. https://doi.org/10.1017/S1368980017000180

Gundersen, C., Kreider, B., \& Pepper, J. (2011). The economics of food insecurity in the United States. Applied Economic Perspectives and Policy, 33(3), 281-303. https://doi.org/10.1093/aepp/ppr022

Gundersen, C., \& Ziliak, J. P. (2015). Food insecurity and health outcomes. Health Affairs, 34(11), 1830-1839. https://doi.org/10.1377/hlthaff.2015.0645

Hernandez, D. C., Reesor, L. M., \& Murillo, R. (2017). Food insecurity and adult overweight/obesity: Gender and race/ethnic disparities. Appetite, 117, 373-378. https://doi.org/10.1016/j.appet.2017.07.010

Huggins, J. C. (2017). A cartographic perspective on the correlation between redlining and public health in Austin, Texas-1951. Cityscape, 19(2), 267-280. https://www.huduser.gov/portal/periodicals/cityscpe/vol19num2/article19.html 
Janda, K. M., Dominguez, D. S., Ranjit, N., Hoelscher, D. M., Price, A., \& van den Berg, A. (2021). Mapping food insecurity-related 2-1-1 calls in a 10-county area of central Texas by zip code: Exploring the role of geographic food access, urbanicity and demographic indicators. Journal of Community Health, 46(1), 86-97. https://doi.org/10.1007/s10900-020-00847-3

Jones, A. D., Hoey, L., Blesh, J., Janda, K., Llanque, R., \& Aguilar, A. M. (2018). Peri-urban, but not urban, residence in Bolivia is associated with higher odds of co-occurrence of overweight and anemia among young children, and of households with an overweight woman and stunted child. The Journal of Nutrition, 148(4), 632-642. https://doi.org/10.1093/in/nxy017

Jones, A. D., Ngure, F. M., Pelto, G., \& Young, S. L. (2013). What are we assessing when we measure food security? A compendium and review of current metrics. Advances in Nutrition, 4(5), 481-505. https://doi.org/10.3945/an.113.004119

Laborde, D., Martin, W., \& Vos, R. (2020). Poverty and food insecurity could grow dramatically as COVID-19 spreads. In J. Swinnen \& J. McDermott (Eds.), Part one: Food security, poverty, and inequality (Chapter 2, pp. 16-19). International Food Policy Research Institute (IFPRI). https://doi.org/10.2499/p15738coll2.133762_02

Larson, N. I., Story, M. T., \& Nelson, M. C. (2009). Neighborhood environments: Disparities in access to healthy foods in the US. American Journal of Preventive Medicine, 36(1), 74-81.e10. https://doi.org/10.1016/i.amepre.2008.09.025

Leung, C. W., \& Zhou, M. S. (2020). Household food insecurity and the association with cumulative biological risk among lower-income adults: Results from the National Health and Nutrition Examination Surveys 2007-2010. Nutrients, 12(5), 1517. https://doi.org/10.3390/nu12051517

Linnan, L. A. (2012). Research collaboration with 2-1-1 to eliminate health disparities: An introduction. American Journal of Preventive Medicine, 43(6), S415-S419. https://doi.org/10.1016/j.amepre.2012.09.025

Loopstra, R., Reeves, A., McKee, M., \& Stuckler, D. (2016). Food insecurity and social protection in Europe: Quasinatural experiment of Europe's great recessions 2004-2012. Preventive Medicine, 89, 44-50. https://doi.org/10.1016/j.ypmed.2016.05.010

Morales, A. (2011). Marketplaces: Prospects for social, economic, and political development. Journal of Planning Literature, 26(1), 3-17. https://doi.org/10.1177/0885412210388040

Morales, D. X., Morales, S. A., \& Beltran, T. F. (2020). Racial/ethnic disparities in household food insecurity during the Covid-19 pandemic: A nationally representative study. Journal of Racial and Ethnic Health Disparities, 7(5), 1-15. https://doi.org/10.1007/s40615-020-00892-7

Niles, M. T., Bertmann, F., Belarmino, E. H., Wentworth, T., Biehl, E., \& Neff, R. A. (2020). The early food insecurity impacts of COVID-19. Nutrients, 12(7), Article 2096. https://doi.org/10.1101/2020.05.09.20096412

O’Connell, K. E., Holben, D. H., \& Holcomb, J. P. (2008). Use of food pantries is associated with household food insecurity in Ohio. Journal of Hunger \& Environmental Nutrition, 2(2-3), 93-109. https://doi.org/10.1080/19320240801891503

Odoms-Young, A. M., \& Marino, B. (2018). Examining the impact of structural racism on food insecurity: Implications for addressing racial/ethnic disparities. Family \& Community Health, 41(Suppl 2), S3. https://doi.org/10.1097/FCH.0000000000000183

Office of the Texas Governor. (2020, May 12). Governor Abbott, HHSC announce over \$1 billion in pandemic food benefits for Texas families. https://gov.texas.gov/news/post/governor-abbott-hhsc-announce-over-1-billion-in-pandemic-foodbenefits-for-texas-families

Osborn, C. (2020, July 5). ICUs could be overrun in 10 days amid coronavirus spike, Austin mayor says. Austin AmericanStatesman. https://www.statesman.com/news/20200705/icus-could-be-overrun-in-10-days-amid-coronavirus-spikeaustin-mayor-says

Pan, L., Sherry, B., Njai, R., \& Blanck, H. M. (2012). Food insecurity is associated with obesity among US adults in 12 states. Journal of the Academy of Nutrition and Dietetics, 112(9), 1403-1409. https://doi.org/10.1016/j.jand.2012.06.011

Pérez-Escamilla, R., Cunningham, K., \& Moran, V. H. (2020). COVID-19 and maternal and child food and nutrition insecurity: a complex syndemic. Maternal \& Child Nutrition, 16(3), Article e13036. https://doi.org/10.1111/mcn.13036 
Pinstrup-Andersen, P. (2009). Food security: Definition and measurement. Food Security, 1(1), 5-7. https://doi.org/10.1007/s12571-008-0002-y

R Team, (2017). R: A Language and Environment for Statistical Computing. [Computer Software]. R Foundation for Statistical Computing.

Robaina, K. A., \& Martin, K. S. (2013). Food insecurity, poor diet quality, and obesity among food pantry participants in Hartford, CT. Journal of Nutrition Education and Behavior, 45(2), 159-164. https://doi.org/10.1016/j.jneb.2012.07.001

Rodgers, J. T., \& Purnell, J. Q. (2012). Healthcare navigation service in 2-1-1 San Diego: Guiding individuals to the care they need. American Journal of Preventive Medicine, 43(6), S450-S456. https://doi.org/10.1016/j.amepre.2012.08.012

Savas, L. S., Fernández, M. E., Jobe, D., \& Carmack, C. C. (2012). Human papillomavirus vaccine: 2-1-1 helplines and minority parent decision-making. American Journal of Preventive Medicine, 43(6), S490-S496. https://doi.org/10.1016/i.amepre.2012.09.003

Saxton, M. L., Naumer, C. M., \& Fisher, K. E. (2007). 2-1-1 Information services: Outcomes assessment, benefit-cost analysis, and policy issues. Government Information Quarterly, 24(1), 186-215. https://doi.org/10.1016/j.giq.2006.02.013

Schanzenbach, D., \& Pitts, A. (2020, June 10). How much has food insecurity risen? Evidence from the Census Household Pulse Surve. Northwestern Institute for Policy Research. https://www.ipr.northwestern.edu/documents/reports/ipr-rapid-research-reports-pulse-hh-data-10-june-2020.pdf

Schanzenbach, D., \& Tomeh, N. (2020). State levels of food insecurity during the COVID-19 crisis. Northwestern Institute for Policy Research. https://www.ipr.northwestern.edu/documents/reports/ipr-rapid-research-reports-app-visualizesfood-insecurity-14-july-2020.pdf

Seligman, H. K., Bindman, A. B., Vittinghoff, E., Kanaya, A. M., \& Kushel, M. B. (2007). Food insecurity is associated with diabetes mellitus: Results from the National Health Examination and Nutrition Examination Survey (NHANES) 1999-2002. Journal of General Internal Medicine, 22(7), 1018-1023. https://doi.org/10.1007/s11606-007-0192-6

Seligman, H. K., Laraia, B. A., \& Kushel, M. B. (2009). Food insecurity is associated with chronic disease among lowincome NHANES participants. The Journal of Nutrition, 140(2), 304-310. https://doi.org/10.3945/jn.109.112573

Seligman, H. K., \& Schillinger, D. (2010). Hunger and socioeconomic disparities in chronic disease. New England Journal of Medicine, 363(1), 6-9. https://doi.org/10.1056/NEJMp1000072

Shanks, C. B., Hingle, M. D., Parks, C. A., \& Yaroch, A. L. (2020). The COVID-19 pandemic: A watershed moment to strengthen food security across the US food system. American Journal of Public Health, 110(8), 1133-1134. https://doi.org/10.2105/AJPH.2020.305760

StataCorp. (2015). Stata Statistical Software: Release 14. StataCorp, LP. https://www.stata.com/

United Way for Greater Austin. (2020a). COVID-19 update. https://mailchi.mp/uwatx.org/covid-19-update

United Way for Greater Austin. (2020b). Help starts here: Use connectATX to find up-to-date information regarding COVID-19. http://connectatx.org/

United Way of Central Texas, 2019. (2018) Community needs and trends report. http://www.unitedwayaustin.org/wpcontent/uploads/2019/03/Community-Needs-Trends-Report MR.pdf

U.S. Census Bureau, (2018). 2013-2017 American community survey 5-Year estimates. American Community Survey. https://www.census.gov/programs-surveys/acs/technical-documentation/table-and-geography-changes/2017/5year.html

U.S. Department of Agriculture Economic Research Service [USDA ERS]. (2019). Key statistics \& graphics. https://www.ers.usda.gov/topics/food-nutrition-assistance/food-security-in-the-us/key-statistics-graphics.aspx

Walker, R. E., Keane, C. R., \& Burke, J. G. (2010). Disparities and access to healthy food in the United States: A review of food deserts literature. Health \& Place, 16(5), 876-884. https://doi.org/10.1016/j.healthplace.2010.04.013

Weber, A. (2020, March 13). Gov. Abbott issues disaster declaration amid COVID-19 outbreak. KUT 90.5. https://www.kut.org/post/gov-abbott-issues-disaster-declaration-amid-covid-19-outbreak

Wolfson, J. A., \& Leung, C. W. (2020). Food insecurity and COVID-19: Disparities in early effects for US adults. Nutrients, 12(6), Article 1648. https://doi.org/10.3390/nu12061648 


\section{Appendix}

Figure A. Map of Demographic Data of Travis County by Zip Code Using 2018 American Community Survey Data

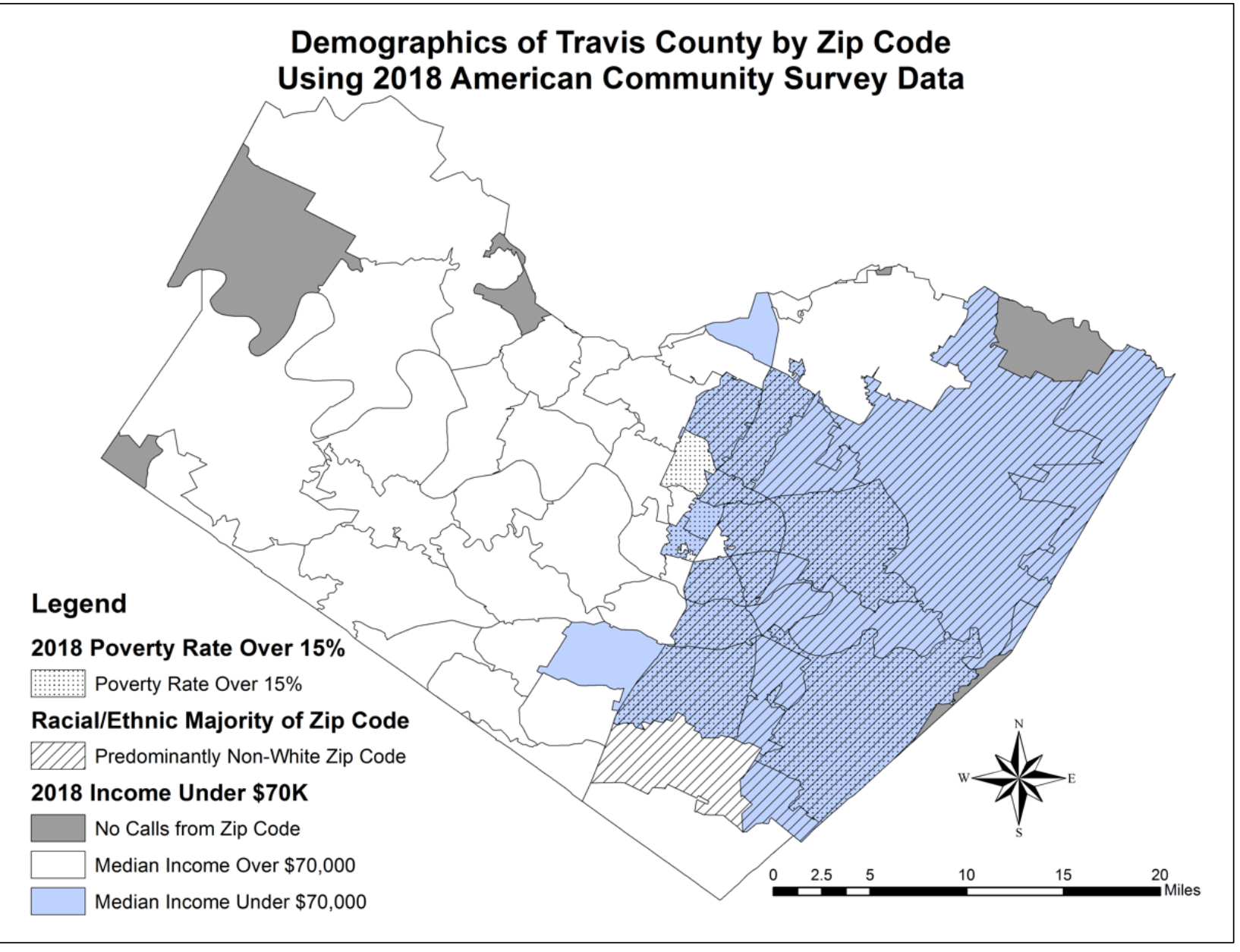

